\title{
UTILIZAÇÃO DE BIOMASSA PARA AUMENTO DA TEMPERATURA DE SECAGEM DE PELOTAS DE MINÉRIO DE FERRO NOS FORNOS DE GRELHA MÓVEL DA SAMARCO MINERAÇÃO S.A.*
}

Gustavo Eduardo Praes ${ }^{1}$ Maurício Cota Fonseca ${ }^{2}$ Maycon Athayde ${ }^{3}$ Sérgio Nunes ${ }^{4}$ Felipe Garcia ${ }^{5}$ Alcides Garcia ${ }^{6}$ Artur Tôrres Filho

\section{Resumo}

A Samarco Mineração S.A., nos últimos anos estudou diversas alternativas para a substituição dos combustíveis fósseis por combustíveis renováveis (Biomassa) em seus fornos de pelotização tipo "Traveling Grate" (grelha móvel). Avaliou-se o uso de carvões vegetais, de eucalipto e de capim elefante, em substituição total ao antracito na composição da mistura. Estudou-se gaseificação em planta piloto, foi realizado um modelamento computacional do uso de gás de síntese e a comparação com os combustíveis tradicionais utilizados em fornos de pelotização de grelha móvel da Samarco. Os trabalhos iniciais foram realizados em escala de laboratório (Pot Grate). Em 2014 foi realizado um teste industrial, com um combustor de biomassa piloto acoplado ao duto que direciona o ar quente para a região de secagem ascendente do forno 02 da Samarco Mineração S.A. O teste ocorreu entre 27 de janeiro a 21 de julho de 2014. Realizou-se uma avaliação detalhada da engenharia deste sistema e de seus impactos no forno de pelotização. $O$ combustor consiste em um sistema para queima de biomassa, o qual gera os gases quentes a serem introduzidos no sistema. Dependendo da configuração, o sistema poderá elevar a temperatura dos gases de secagem em até $75^{\circ} \mathrm{C}$, quando comparado a uma situação de referência.

Palavras-chave: Biomassa; Combustor; Travelling grate.

\section{USAGE OF BIOMASS TO INCREASE TEMPERATURE IN IRON ORE PELLET DRYING IN TRAVELING GRATE KILN IN SAMARCO MINERAÇÃO S.A.}

\author{
Abstract \\ Samarco Mineração SA in recent years has been studied several alternatives to change fossil \\ fuels to renewable fuels (biomass) in its Traveling Grate Kilns. It was evaluated the use of \\ charcoals from eucalyptus and elephant grass, in total replacement of anthracite in the \\ composition of the mixture. Gasification was studied in a pilot plant, it was performed a \\ computational modeling of the synthesis gas usage and the comparison with traditional fuels \\ used in pelletizing traveling grate kiln. In 2014 it was conducted an industrial test with a pilot \\ biomass burner coupled to the duct that directs the hot air to the up draft drying 2 of the Traveling \\ Grate Machine 2. The test was the pioneer with Biomass in Samarco, occurred in the period of \\ January 27 to July 21 of 2014. It was performed a detailed evaluation of the engineering of this \\ system and its impact on the Traveling Grate Kiln. The burner consists of a system for burning \\ biomass, which generates hot gases to be introduced into the system. Depending on the \\ configuration, the system can raise the temperature of the Downdraft Draft Drying Zone until \\ $75^{\circ} \mathrm{C}$ (from $175^{\circ} \mathrm{C}$ to $250^{\circ} \mathrm{C}$ ), when compared to a baseline. \\ Keywords: Biomass; Burner; Traveling grate. \\ 1 Eng. Químico, Bacharel, Eng. Especialista Pleno, Gerência Geral de Tecnologia e Ecoeficiência, Samarco \\ Mineração S.A, Anchieta, ES, Brasil. \\ 2 Eng. Metalurgista, Mestre, Eng. Especialista Sênior, Gerência Geral de Tecnologia e Ecoeficiência, Samarco \\ Mineração S.A, Anchieta, ES, Brasil. \\ 3 Eng. Metalurgista, Mestre, Eng. Sênior, Gerência Geral de Operações, Samarco Mineração S.A, Anchieta, ES, \\ Brasil. \\ 4 Eng. Metalurgista, Mestre, Eng. Especialista Sênior, Gerência Geral de Operações, Samarco Mineração S.A, \\ Anchieta, ES, Brasil. \\ 5 Engenheiro Mecânico, Bacharel, Engenheiro Especialista, AGE Engenharia, São Paulo, SP, Brasil. \\ 6 Engenheiro Mecânico, Bacharel, Diretor Técnico, AGE Engenharia, São Paulo, SP, Brasil. \\ 7 Eng. Agrônomo e Sanitarista, Doutor, Diretor Técnico, Engenho Nove Engenharia Ambiental LTDA, Nova Lima, \\ MG, Brasil.
}




\section{INTRODUÇÃO}

A Samarco Mineração S.A., nos últimos anos estudou diversas alternativas para a substituição dos combustíveis fósseis por combustíveis renováveis.

Os estudos desenvolvidos foram:

2000 - Utilização de carvão vegetal de eucalipto em substituição ao antracito na mistura. Os testes de laboratório mostraram uma queda da qualidade física (maior volume para a mesma dosagem em $\mathrm{kg} / \mathrm{tms}$ );

2001 - Testes em Pot Grate utilizando carvão de Capim Elefante em substituição ao antracito na mistura. Foram testados dois tipos de carvão de capim elefante;

2003 a 2005 - Foi preparada uma área experimental na Samarco para o plantio de Capim Elefante ( 8ha). Em 2004 ocorreu o primeiro corte para a obtenção de dados preliminares de plantio. A amostra foi transformada em carvão utilizando-se o processo de pirólise DPC. Em 2005 foram realizados os testes de caracterização do carvão produzido e ensaios de pot grate (pelotamento e queima). Além da queda de qualidade física, os teores de Sódio e Potássio no carvão mostraram-se elevados, o que comprometeria a qualidade química das pelotas além de levar a desgaste acentuado do refratário do forno (foram realizados testes em laboratório simulando a queima deste carvão). A partir deste estudo surgiu um novo conceito, que seria a geração de energia fora do sistema e a transferência da mesma para o forno, minimizando as interferências nos equipamentos e na qualidade das pelotas.

2005 - Início de operação do sistema de injeção de carvão pulverizado no forno 02. O sistema apresentou algumas dificuldades operacionais, principalmente pelo alto teor de cinzas no antracito. Atualmente opera apenas com coque de petróleo, quando há disponibilidade do insumo.

2008 - Em um momento de descoberta de novas tecnologias e considerando as premissas anteriores, em especial o conceito de geração de energia fora do sistema e a transferência desta energia para o forno, de maneira a preservar os equipamentos e a qualidade das pelotas, a empresa começou a estudar o processo de gaseificação, através de testes com resíduos agrícolas fora da Samarco.

2012 - Retomada dos estudos de gaseificação de biomassa, com a mensuração do volume e da massa de madeira (cubagem) da floresta de eucaliptos da Samarco em Ponta de Ubu, Anchieta/ES.

2013 - Foram realizados três estudos conceituais exclusivos para biomassa em fornos de grelha móvel em parceria com a Universidade Finlandesa LUT (Lappeeranta University of Technology):

- Flow_calculations_Report (Uso de gás de síntese);

- Comparison of Biomass Gasification Technologies for Natural Gas Substitution in Iron Ore Pelletizing Plants;

- Biomass Usage in Traveling Grate Process.

Ambos os estudos mostraram que é tecnicamente possível utilizar o processo de gaseificação de biomassa em fornos de pelotização.

2013 e 2014 - Com todo o conhecimento acumulado, a empresa optou por utilizar resíduos de madeira gerados nas construções de suas duas últimas usinas em um teste industrial, para geração de gases quentes a serem introduzidos no sistema. A meta inicial era processar (queimar) 480 toneladas de resíduo de madeira. O teste ocorreu no primeiro semestre de 2014 buscando ser uma fonte extra e externa de calor para a secagem ascendente para o forno de pelotização. Os principais objetivos do teste foram: 
- Queimar o resíduo de madeira gerado na Samarco, o que seria uma solução interna para o tratamento do mesmo (este resíduo era destinado para aterro, gerando custos);

- Levantar informações relevantes, durante o período de operação do combustor, para o desenvolvimento de combustor de maior porte, o qual utilizará madeira picada de origem florestal, avaliando as possibilidades de incrementos de temperatura dos gases de secagem.

As Usinas \#1 e \#2 da Samarco apresentam um conceito de projeto concebido para minérios hematíticos compactos, composição bem diferente da atual que utiliza minérios Goethiticos que são muito hidratados. Muitos desenvolvimentos ocorreram no processo da Samarco ao longo dos anos e algumas se destacam, como por exemplo, o uso do carvão mineral na pelota crua e o uso da prensa de rolos. Estas melhorias levaram a um aumento da produção, muito além da capacidade projetada para as usinas antigas, e com minérios muito diferentes e de processamento difícil. O resultado é que os fornos não acompanharam estas melhorias e a etapa de secagem das pelotas foi a mais afetada, apresentando temperaturas abaixo das ideais, comprometendo o processo de secagem. Isso levou à instalação deste sistema visando aumentar a temperatura dos gases de secagem.

\section{MATERIAIS E MÉTODOS}

O desenvolvimento do combustor ocorreu em duas etapas. A primeira etapa foi o teste industrial com o combustor piloto, e seus equipamentos auxiliares (picador de madeiras, transportadores, etc). O combustor para a geração de gases quentes foi acoplado ao duto do ventilador 85VT05, que direciona os gases quentes para a etapa de secagem ascendente II (Usina \#02).

A planta piloto para execução do teste industrial era composta dos seguintes:

- Um picador de madeira;

- Uma câmara de combustão;

- Seis combustores, posicionados em pares conforme desenho da Figura 1.
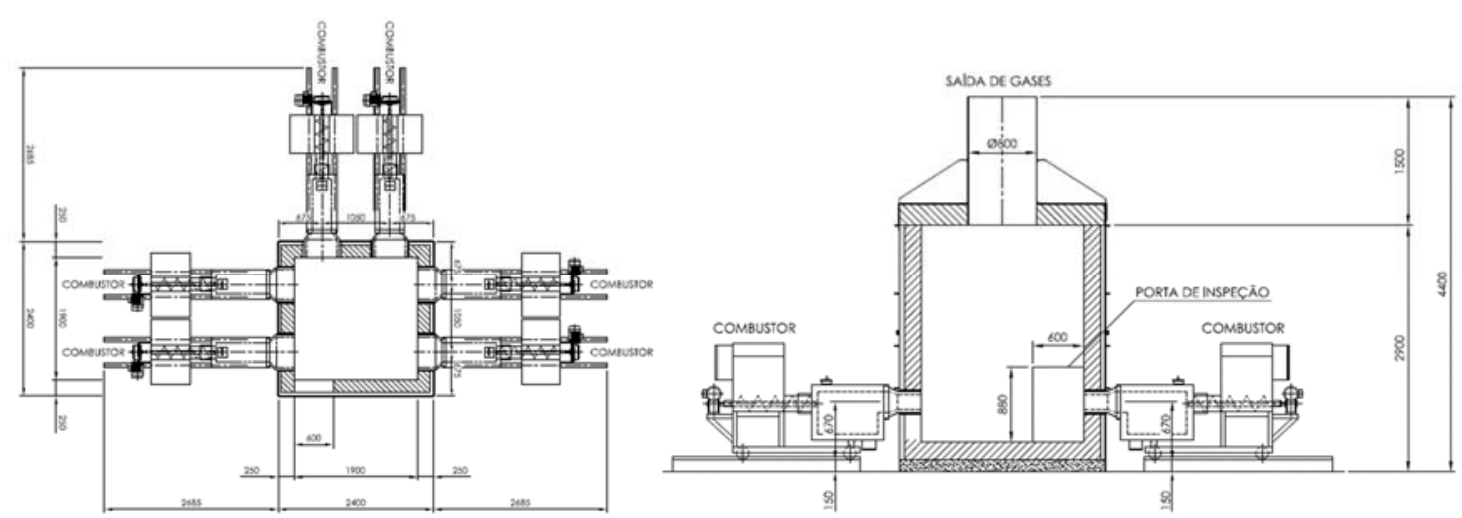

Figura 1: Desenho do arranjo do combustor.

A capacidade do sistema era para o processamento de 1 tonelada de madeira picotada por hora $(\sim 3.000 .000 \mathrm{kcal} / \mathrm{h})$. A alimentação dos combustores era realizada manualmente. A equipe que operava o sistema era composta de 10 operadores. 0 fluxo do processo está demonstrado na Figura 2. 


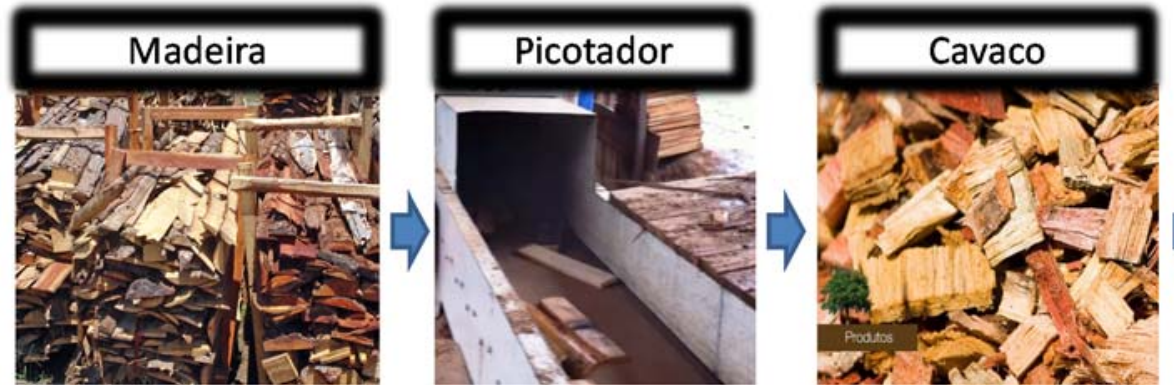

Figura 2: Fluxo do processo de queima da biomassa

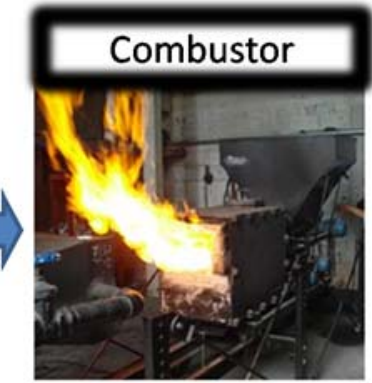

Os gases resultantes da combustão no sistema foram direcionados para o duto de gases quentes do ventilador 85VT05, que realizarão a secagem ascendente II, conforme a seta vermelha na Figura 3:
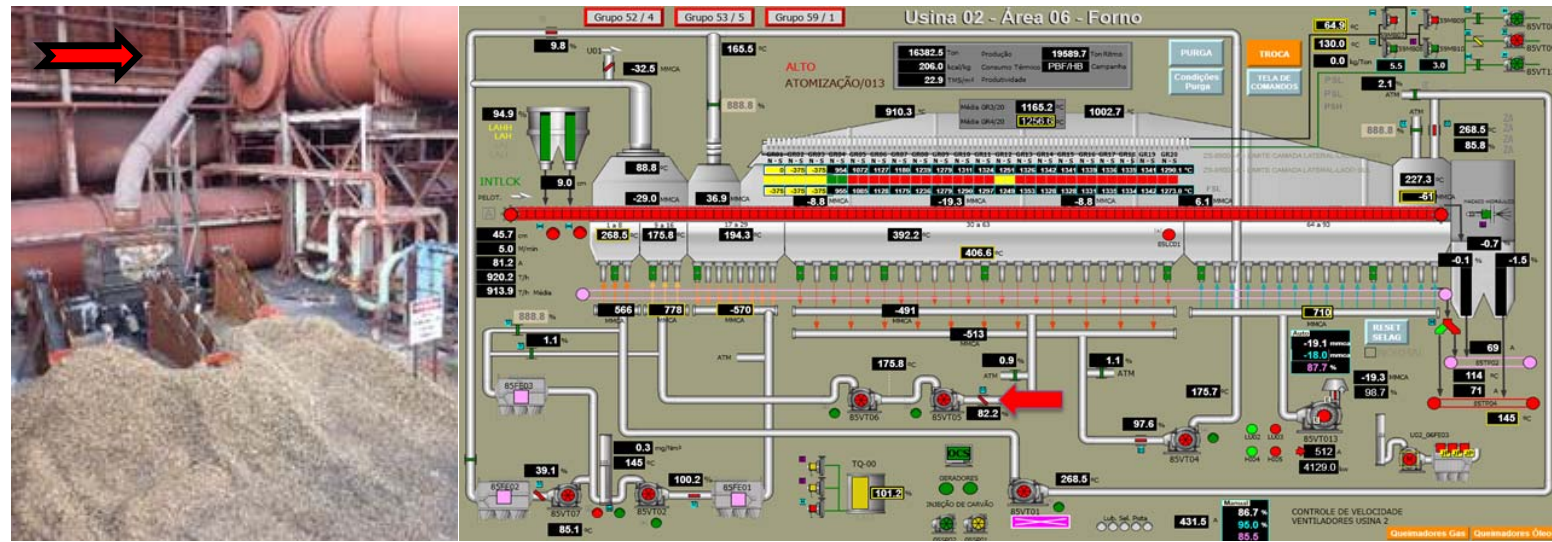

Figura 3: Ponto de inserção dos gases gerados pelo combustor.

$\mathrm{Na}$ segunda etapa foram realizadas simulações com diferentes inserções de calor nas secagens, variando-se a quantidade da biomassa processada, avaliando-se do ponto de vista termodinâmico o impacto no forno de pelotização. Foram realizados os cálculos de transferência de calor, massa e balanço termodinâmico, partindo da situação de referência na Figura 4.

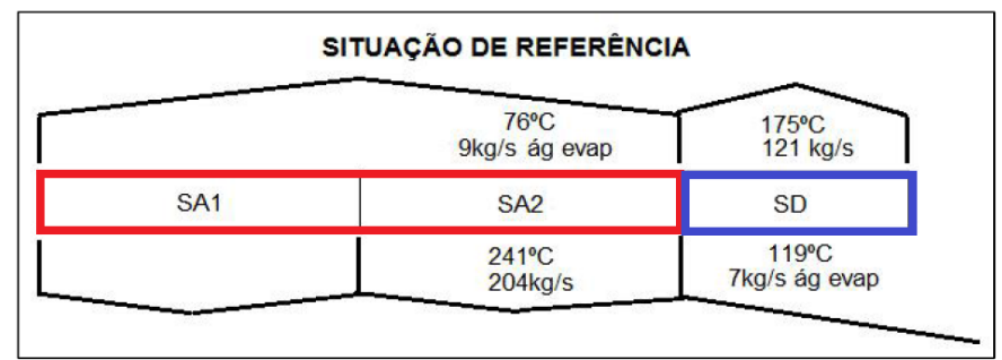

Figura 4: Desenho esquemático da situação referência.

Com os resultados obtidos, foi realizado todo o projeto conceitual de um sistema de picadores, pátio de toras, movimentação e picagem de madeira, transporte de biomassa e queima de biomassa em um novo combustor (Gerador de Gases Quentes) para ser implementado no futuro. 


\section{RESULTADOS E DISCUSSÕES}

Em relação ao teste industrial com a planta piloto, o gráfico da Figura 5 abaixo mostra a evolução da quantidade de madeira processada. No total foram processadas 484 toneladas de madeira nos dias de operação.

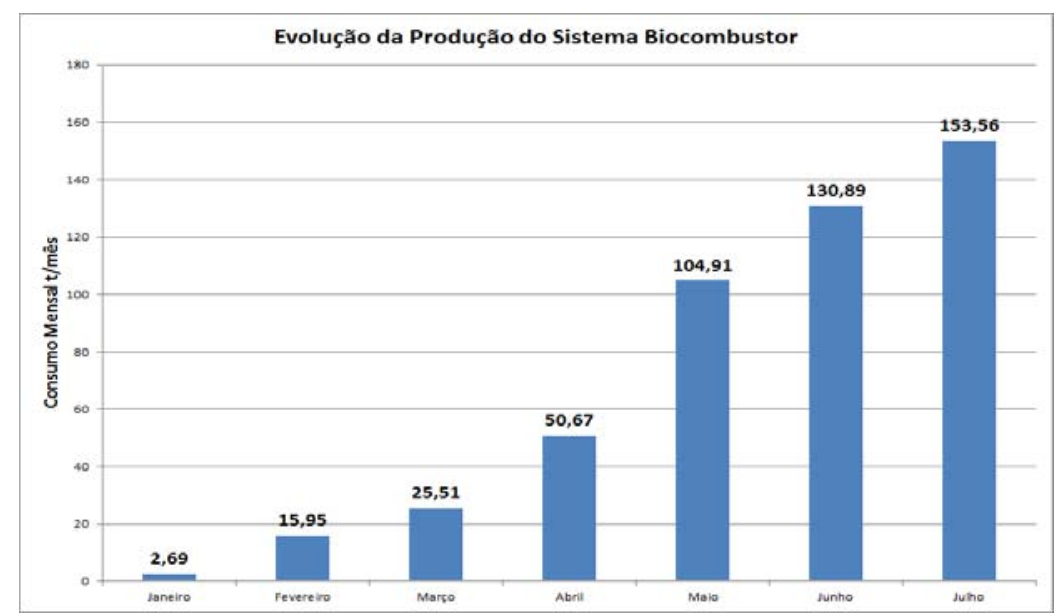

Figura 5 - Histórico do consumo mensal de madeira pelo combustor.

O combustor operava de forma intermitente, de segunda a sexta usualmente, das $08 \mathrm{~h} 30 \mathrm{~min}$ às $16 \mathrm{~h} 30 \mathrm{~min}$. A operação intermitente foi um sério problema, pois com o aquecimento e o resfriamento do sistema em todos os dias de operação, ficou evidente que não era possível ter uma estabilidade operacional no processo, o que gerava uma série de consequências, como por exemplo, o desgaste de refratário. A média da temperatura durante todos os dias de operação foi da ordem de $447^{\circ} \mathrm{C}$, representado na Figura 6.

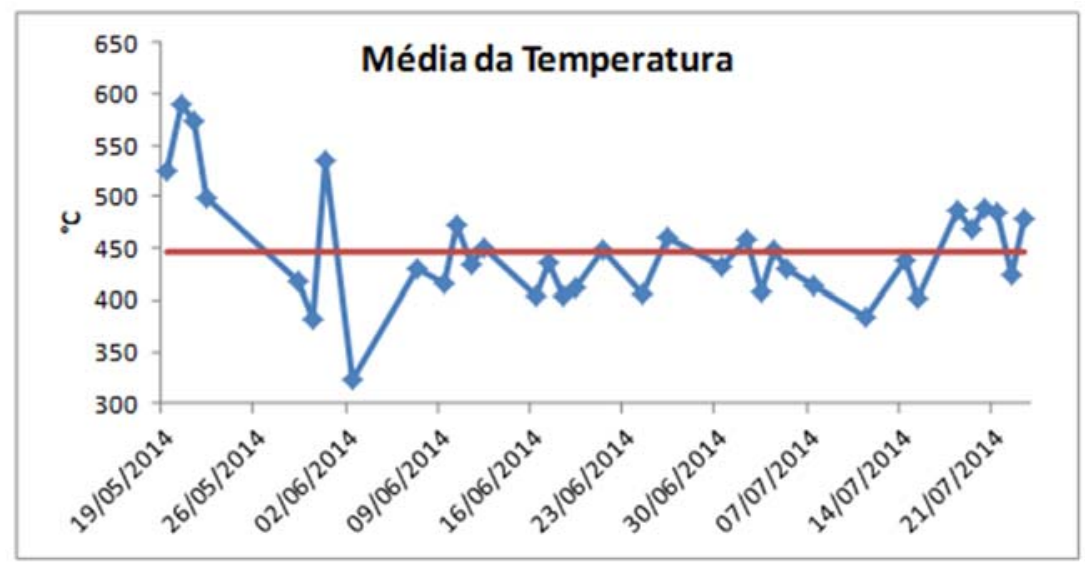

Figura 6 - Histórico da média da temperatura dos gases gerados pelo combustor.

Os maiores desafios enfrentados pelo teste foram:

- Necessidade de intervenção humana direta, alimentações manuais, muitos entupimentos, funcionamento intermitente dos combustores. Tudo isso levou a uma baixa produtividade;

- Reduzido nível de automação e instrumentação.

- Estoque da madeira picada no tempo;

- Circuito de ventilação de gases não foi o adequado para o teste; 
As lições aprendidas foram:

- Necessário haver sistema de armazenamento adequado;

- Processo de combustão e recuperação calor necessita serem bem projetados para não impactarem negativamente nas operações (forno de pelotização e combustor);

- O ideal é a operação contínua, que levará a uma redução na instabilidade operacional, do desgaste de refratário e das perdas térmicas;

A Figura 7 a seguir apresenta o comportamento da temperatura no período de maior consumo de biomassa (maio a julho 2014). Nos melhores momentos da operação a temperatura dos gases chegou a atingir $800^{\circ} \mathrm{C}$ e pela deficiência no sistema de alimentação dos combustores não era possível manter este patamar por muito tempo.

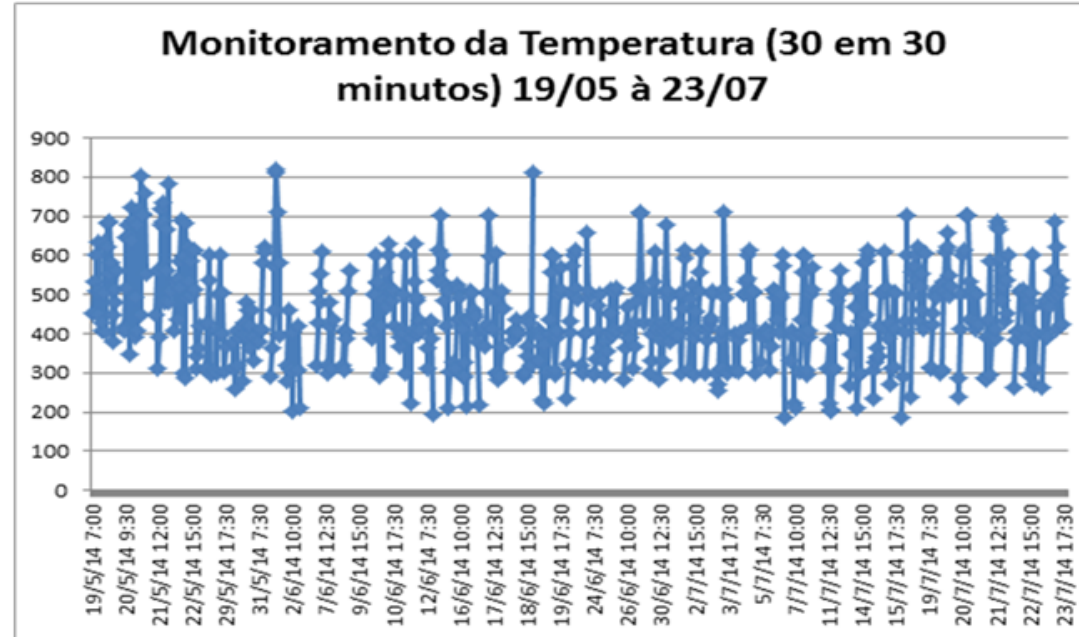

Figura 7 - Histórico da média da temperatura dos gases gerados pelo combustor.

Economicamente o teste apresentou retorno nulo, a escala pequena, isto é pequena quantidade de resíduos não permitiu que ocorressem ganhos econômicos.

Quanto às simulações realizadas, estudou-se 5 opções para elevar a temperatura dos gases de secagem, com diferentes pontos de inserção:

- SD250 Elevação da temperatura dos gases da secagem descendente para $250^{\circ} \mathrm{C}$;

- SD350 Elevação da temperatura dos gases da secagem descendente para $350^{\circ} \mathrm{C}$;

- SA280 Elevação da temperatura dos gases da secagem ascendente 2 para $322^{\circ} \mathrm{C}$;

- SA322 Elevação da temperatura dos gases da secagem ascendente 2 para $322^{\circ} \mathrm{C}$;

- SA322/SD250 Elevação da temperatura dos gases de alimentação da secagem ascendente 2 para $322^{\circ} \mathrm{C}$ e da secagem descendente para $250^{\circ} \mathrm{C}$.

A Figura 8 apresenta resumo destas análises. 


\begin{tabular}{|c|c|c|c|c|}
\hline Código & Opção & Temperatura $\left({ }^{\circ} \mathrm{C}\right)$ & $\begin{array}{c}\text { Carga Térmica Biomassa } \\
(\% \text { da energia Forno 2) }\end{array}$ & $\begin{array}{c}\text { Aumento do Consumo } \\
\text { Específico (\% Forno 2) }\end{array}$ \\
\hline SD250 & $\begin{array}{c}\text { Secagem } \\
\text { Descendente }\end{array}$ & 250 & $4,2 \%$ & $0,3 \%$ \\
\hline SD350 & $\begin{array}{c}\text { Secagem } \\
\text { Descendente }\end{array}$ & 350 & $9,4 \%$ & $0,9 \%$ \\
\hline SA280 & $\begin{array}{c}\text { Secagem } \\
\text { Ascendente }\end{array}$ & 280 & $3,8 \%$ & $0,7 \%$ \\
\hline SA322 & $\begin{array}{c}\text { Secagem } \\
\text { Ascendente }\end{array}$ & 322 & $7,8 \%$ & $2,2 \%$ \\
\hline SA322/SD250 & $\begin{array}{c}\text { Secagem } \\
\text { Ascendente e }\end{array}$ & 250 & $11,9 \%$ & $2,5 \%$ \\
\hline
\end{tabular}

Figura 8 - Análise da carga térmica gerada pela queima da biomassa.

A opção SD250 traz o menor impacto para o forno, pois considera o aumento da temperatura da secagem descendente em relação à situação de referência de $175^{\circ} \mathrm{C}$ para $250^{\circ} \mathrm{C}$. Esta opção foi considerada para o projeto de um novo combustor. Este projeto foi escolhido para avaliação econômica e de engenharia devido as seguintes razões:

- É uma opção de menor carga térmica e para início do projeto seria uma área relativamente pequena, na qual o projeto não demandaria significativo impacto na região.

- Esta opção mostra-se melhor, pois é uma das opções de menor carga térmica útil, isto é $4,2 \%$ do total da Usina 2 e consequentemente com menor CAPEX. No caso o projeto estudado, pátio de toras, ciclos de descarregamento e carga de madeira, picadores, armazenagem, transporte e gerador de gases quentes estudados são para esta carga térmica.

- Menor impacto no consumo térmico do forno, pois o aumento do consumo térmico é de $0,3 \%$ de pelota, porém utilizando um combustível renovável. Esta análise considerou o mesmo nível de produção.

- Aumento da evaporação em aproximadamente $15 \%$.

O arranjo do projeto do gerador de gases desta opção SD250 é apresentado na figura 9 a seguir:

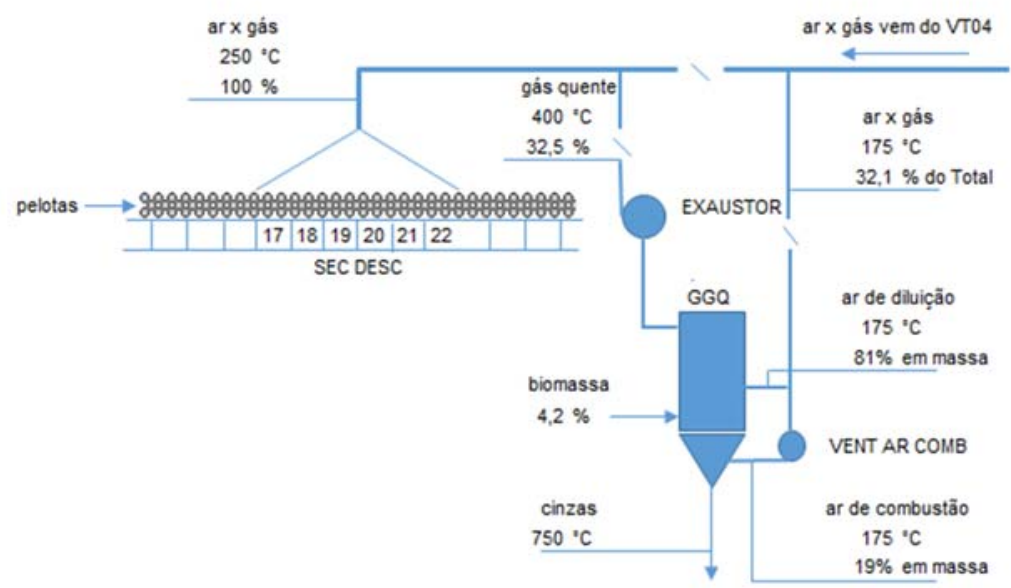

Figura 9 - Arranjo simplificado do sistema para geração de gases quentes. 


\section{CONCLUSÃO}

O teste realizado com o combustor piloto foi bem sucedido, pois foi possível queimar certa quantidade de madeira, pode-se entender o processo de picagem e geração de gases quentes para pelotização (dificuldades, ajustes necessários, gargalos, requerimentos de segurança). Enfim o teste piloto foi uma oportunidade de amadurecimento da Samarco quanto a um possível uso futuro de biomassa.

Entre as alternativas estudas através do estudo de balanço térmico e seu impacto no forno de pelotização optou-se pelo projeto de combustão de biomassa que tem o menor impacto no consumo térmico do forno de pelotização.

A substituição tanto do gás natural quanto do óleo combustível pela biomassa mostrou-se viável. Os ganhos da substituição do óleo combustível viabiliza mais ainda o projeto do ponto de vista econômico.

O projeto possui bases sólidas, pois talvez seja o início do consumo de biocombustíveis na Samarco de forma regular. Os principais atrativos deste projeto são: redução das emissões de gases do efeito estufa, desenvolvimento social da comunidade no entorno da Samarco, além de ganhos financeiros.

\section{BIBLIOGRAFIA}

1 SAMARCO MINERAÇÃO S.A.. Sistema de geração de Energia Térmica Através da Combustão de Biomassa composta por resíduos de madeira da Samarco e sua utilização no Forno 02. Anchieta - Espírito Santo. 2014.

2 AGE Engenharia. Memorial de cálculo: Usina 2 - Geração e Utilização Energia Térmica com Biomassa. São Paulo - São Paulo. 2014.

3 AGE Engenharia. Memorial Descritivo: Aumento de temperatura dos gases de recuperação, Projeto Conceitual. São Paulo - São Paulo. 2014.

4 IPE Brasil Projetos. Estudo de viabilidade de matérias primas para produção energética na SAMARCO MINERAÇÃO S.A. Domingos Martins - Espírito Santo. 2014.

5 SAMARCO MINERAÇÃO S.A.. Levantamento dos tipos de biomassa, mais empregados no mundo para a geração de energia térmica com vistas ao potencial emprego na Samarco. Anchieta - Espírito Santo. 2012.

6 CCA - Centro de Consultoria Ambiental. Relatório sobre a determinação do volume e da massa de madeira aérea de floresta exótica plantada na propriedade rural da Samarco em ponta de Ubu, Anchieta/ES. Guarapari - Espírito Santo. 2012. 